\title{
Korean Traditional Space Creator for Digital Contents
}

\author{
Seungmook Kang ${ }^{1}$ and Hadong Kim $^{2}$ \\ ${ }^{I}$ College of Culture and Creative Industry, Jeonju University, Korea \\ ${ }^{2}$ CGWave Inc., Korea
}

\begin{abstract}
Since 2009, the Korean government began to invest heavily in the field of digital contents based on Korean cultural heritage like Korean dramas, films, animation, and virtual reality application. The investment was caused by Korean Wave, which is the surge of popularity of South Korean culture around the world since the $21^{\text {st }}$ century [1], also called Hallyu in Korean. However the Korean historical dramas and films have misarranged the components of Korean traditional houses and ornaments chronologically and spatially. The typical problem is coming from the lack of reference to who builds the sets. The one of the solutions is Korean Space Creator that has real time renderer to show the created space instantly and the database of traditional Korean house components, then it is easy for digital contents producers to use. At present the application has the specific regional materials of Chosun Dynasty (1392-1910) in database; it will extend to more region and dynasties.
\end{abstract}

Index Terms-Korean Door, Korean Wave, Korean Window, Virtual Space

\section{INTRODUCTION}

In Korea, there are sixteen well preserved villages which show the houses and towns of Chosun Dynasty, 1392-1910, which was the last dynasty before the Republic of Korea. For Korean Wave (Hallyu in Korean), those villages are frequently seen in film and media than ever before because modern cities in Korea aren't much different from the westernized modern cities. Foreigners are more interested in old Korean villages.

The government of Korea announced to put big investment in the field of cultural contents media like films and TV dramas since Korean Wave has been brought by film and media. Korean Wave came from the continental China and spread to Southeast Asia, Europe, even the United States. Also she has paid attention to entertainment industry, a.k.a. creative industry in $\mathrm{UK}$, as it is technology based pollution-free business. By copyright law, all copyrighted materials and contents bring economical income for a certain time period without reproduction. This is the one of the reasons the government decided to invest.

Each home of country under influence of Korean Wave is exposed to Korean cultural contents. The more historical dramas and films deliver to the home, the more chronological problems will be shown and the viewers perceive wrong information. This problem is not limited to the foreigners, but also to the Korean citizens who don't have historical knowledge especially the younger generation.

Manuscript received on March 6, 2008.

E-mail: xeyx@hotmail.com.
The spaces like rooms, living rooms, kitchens, and towns seen on historical dramas should have right components for the period. The application named Han Space Creator has huge database of windows, doors, furniture, ornaments, walls, roads, and formation of houses in town of Chosun Dynasty. It is real time rendering editor to design the location of furniture and ornament in a room, windows and doors in a room, and houses in a town. The chronological background is Chosun Dynasty and instinct menu interfaces let users run it easily. The drama set designers, game background map creators, and animation directors may use the application to build scholastic proven elements of Chosun Dynasty period with several mouse clicks.

\section{DATA COLLECTION}

The sixteen reserved villages are located mostly in southeast and southwest region, called Gyeongsang Province and Jeolla Province respectively. The government chose these villages as the best towns which have kept the houses of Chosun Dynasty. The houses in the town still keep the shape of the original, although several kinds of modification applied for residents' conveniences like water and utility system.

Before collecting the data, I set the fundamental categories to design the historical space for users' conveniences: residential area, which is usual houses, bordering area like walls, community area, where people shared their idea and work together, Confucian rooms, where people practiced ancestor worship, and religion area, where shamanism ritual was being held.

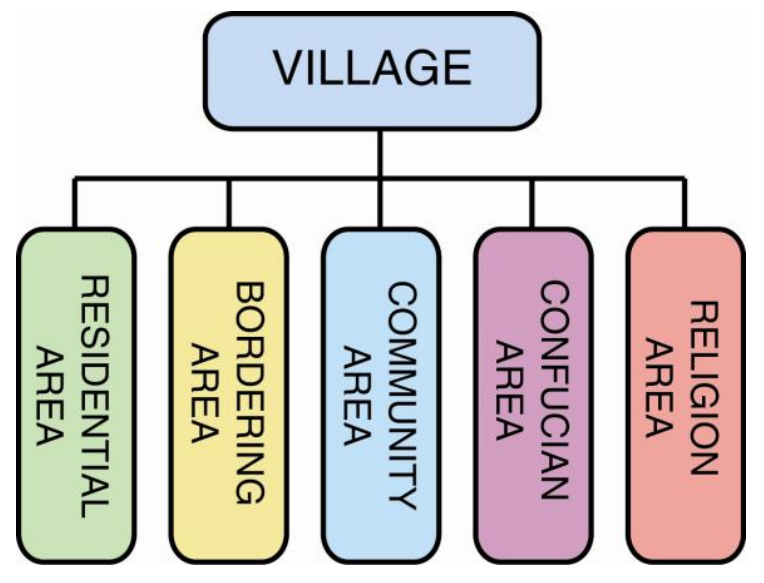

Fig. 1. The Categories

Each category has the basic elements to form the space. The residential area has windows, doors, furniture, and rooms as elementary components. Bordering area means the wall 
between inside of house and outside of house, which divides the houses and roads. Community area is the place where people work together like doing laundry at the public well. Confucianism was not only religion in Chosun, but also it was the standard manual for the way of lives of aristocrats. It is about various manners of ritual, rules and regulations. Shamanism was dominant religion among the citizen and peasants. They prayed to sky, stones, trees and even animals for their fortune.

All the necessary data from the sixteen villages, measuring the dimensions for 3D models and taking photos for texture map, were collected from printed material, online information, and field trip. The amount of collected data is enough to build a virtual town looking like Chosun era. The figure 2 shows the village locations in southern part of the Republic of Korea, a.k.a. South Korea.

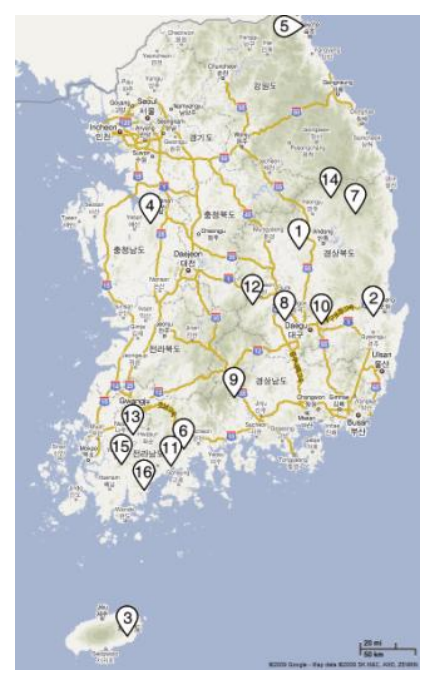

Fig. 2. The location of the villages

\section{APPLICATION}

\subsection{Objective}

The real-time rendering application, called "Han ${ }^{1}$ Space Creator", has simple interface and prospective users run it instinctually. The target users are the people who are working in the field of culture industry, where they create films, dramas, animation, and games. It is useful to make sets for Chosun Dynasty contents since various houses and town information has added to the database.

Also window masters who can make best windows and doors of Chosun style need simulator because they don't have enough proper material like Korean pine tree wood, which is hard-to-find in Korea for economic reason, to make the windows. They once failed to build windows or doors, they can't use them.

For the younger generation, it is good textbook for historical architecture study. The younger people in Korea don't know much about history and tend not to read history books. They like interactive application since they have grown with computer systems, video games and all other high technology device.

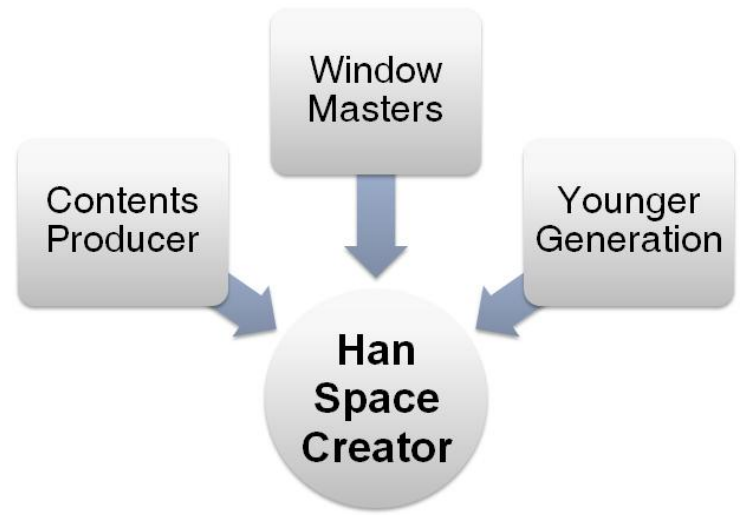

Fig. 3. The prospective users of Han Space Creator

\subsection{Run}

The application is written DirectX based $\mathrm{C}++$, which is running faster than OpenGL based $\mathrm{C} / \mathrm{C}++$ application. As it calculates lighting and shadow in real-time, it consumes much CPU and GPU then programming should be optimized for handling heavy 3D modeling data.

Figure 4 is the diagram of whole application system. It has the connection of database and real-time renderer.

Figure 5 shows the screen shot image of Han Space Creator, displaying aerial view. It has transparent and expandable menu windows then it may be collapsed to view more working area.

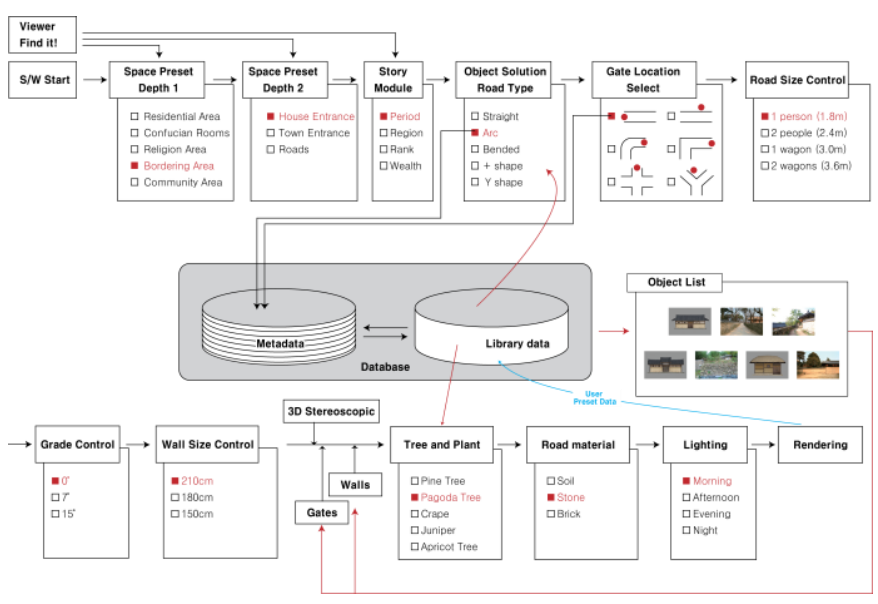

Fig. 4. The Architecture of the application

The application has two parts: navigation mode and editing mode. There's an option for navigation mode, then users can navigate anywhere in the virtual Chosun town. In the mode, user may set the a story mode from community party, wedding ceremony, and ancestor worship, then the automatic navigation starts to let the user look through all the area driven by the application setting. Users can walk and fly around the virtual town, seeing the houses from all the direction in free navigation mode. It is helpful for the user to create the formation of Chosun-like towns.

\footnotetext{
${ }^{1}$ Han stands for Korea written in Chinese character.
} 


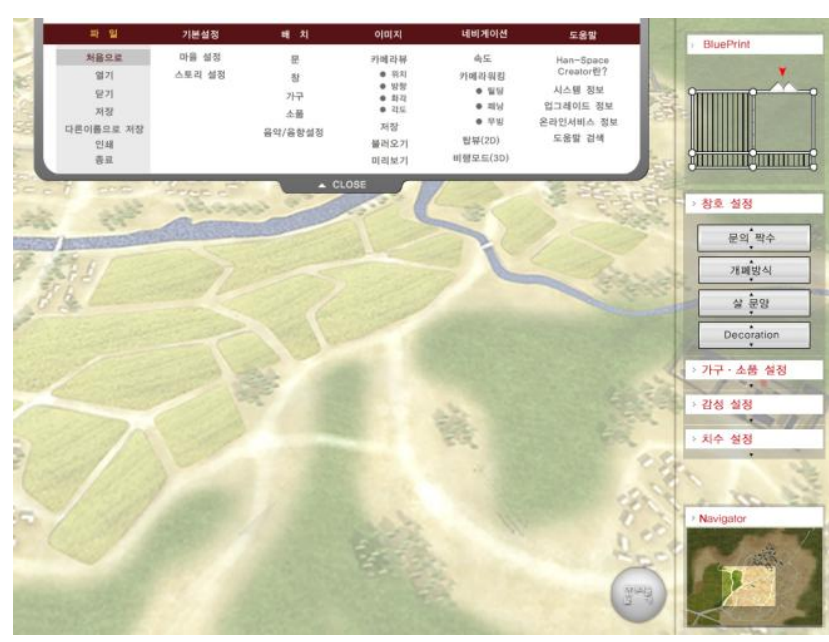

Fig. 5. Screenshot of Han Space Creator

Edit mode let user change the components of the houses and towns. In the room, users can select windows and doors for their favor or for the purpose of the simulation. If they want to set a town for action drama, they may choose stronger looking shape of window but still it is chronologically right Chosun window. Users may not know about the Chosun windows and doors. They don't have to worry about them since this application can solve it. Outside user can select roads by shape, width, and even slope. In Chosun period, the usual road in a town wasn't paved and narrower than the present roads.

TABLE 1: NAVIGATION AND EDIT

\begin{tabular}{|c|l|l|l|}
\hline \multicolumn{2}{|c|}{ Navigation Mode } & \multicolumn{2}{c|}{ Edit Mode } \\
\hline Mree Walk/Fly & $\begin{array}{l}\text { User walk or } \\
\text { fly around by } \\
\text { himself }\end{array}$ & Inside & $\begin{array}{l}\text { Change } \\
\text { windows, } \\
\text { doors, } \\
\text { furniture, } \\
\text { props, and } \\
\text { ornaments }\end{array}$ \\
\hline $\begin{array}{c}\text { Storytelling } \\
\text { Mode }\end{array}$ & $\begin{array}{l}\text { User walk or } \\
\text { fly } \\
\text { automatically } \\
\text { by theme }\end{array}$ & Outside & $\begin{array}{l}\text { Change } \\
\text { roads shape } \\
\text { and width } \\
\text { and walls }\end{array}$ \\
\hline
\end{tabular}

Figure 6 shows the edit mode, where user can change room size, windows, doors, furniture, and props. A room in the house has several different categories, classifying by gender, period, region, social rank, and wealth. After editing, selecting the windows, doors, size of the room, etc., the modified room will be displayed while navigating the town.

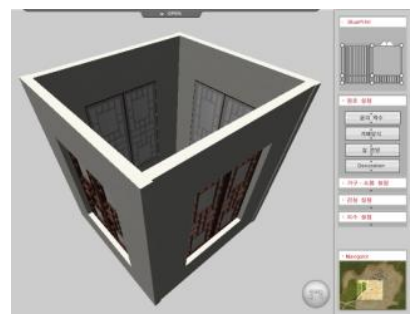

Fig. 6. Edit mode of a room
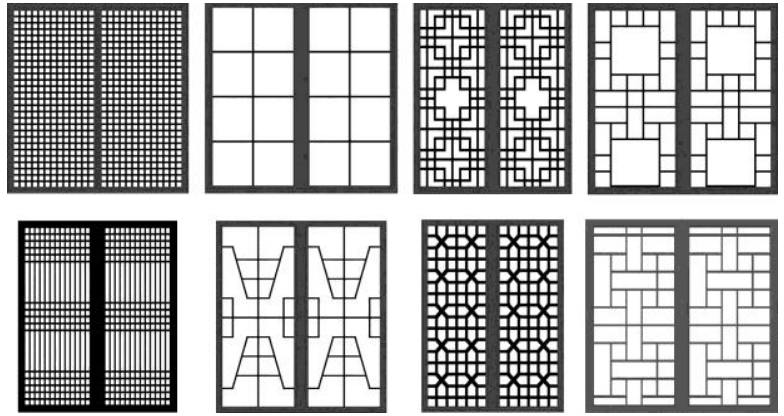

Fig. 7. Windows and doors

Figure 7 is the example shape of windows and doors. The traditional Korean windows and doors have shared the same patterns, where window and door is identified by the size and installed location of a room. The door has a frame from the floor to the ceiling or a bit lower than the ceiling, as a window is installed about $50 \mathrm{~cm}$ (about 19.7 inches) high from the floor. The frame from the floor to the bottom of a window is called "meo-room" in Korean, Figure 8.

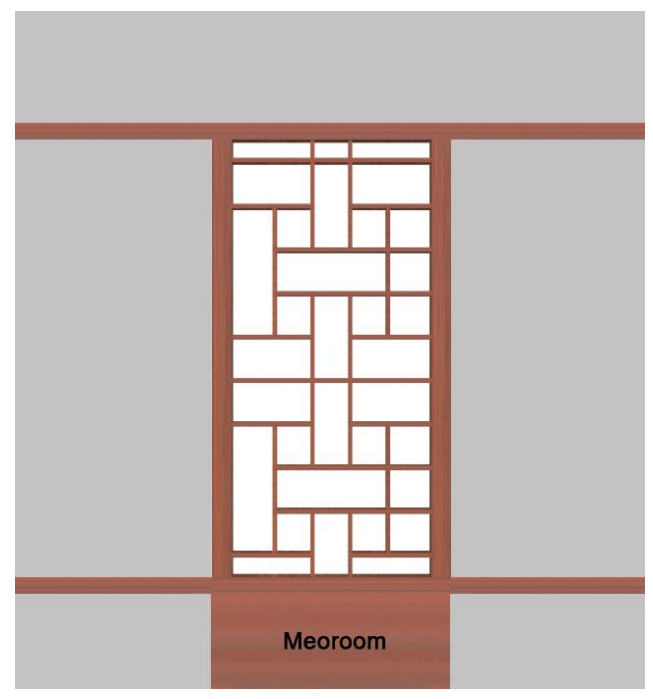

Fig. 8. Meo-room of Korean window

User also can select size of the room. The unit was kan in Korean, one unit of kan is equivalent to $180 \mathrm{~cm}$ (about 70.9 inches). The peasant room was usually $1 \mathrm{kan}$, which was $1 \mathrm{kan} \mathrm{x}$ $1 \mathrm{kan}$, and there were $2 \mathrm{kan}, 3 \mathrm{kan}$, or bigger rooms for aristocrats. The room size was the basic measurement of the whole house size. The house size wasn't bigger than 99 kan; that is 99 kan house was the biggest house in Chosun era for the citizen, only a king had 100 kan or bigger house also called palace. The rooms were classified by genders too according to the philosophy of Confucianism. By the rule, the women were not allowed to work in the society and they were supposed to stay in designated rooms in a house to govern all internal affairs.

Figure 9 is about the size matter of a room that can be edited in the application, Han Space Creator, also the formation of room and floor formation. The room in Chosun had narrow floors called "ma-roo" in Korean. The figure shows the room of $1 \mathrm{kan}$. The circles are wooden columns supporting roof and girder. 


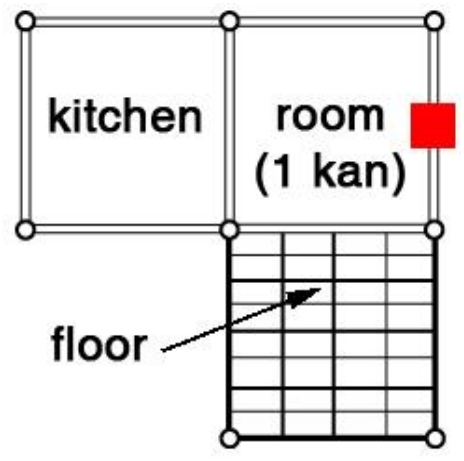

Fig. 9. Formation of a room

There's a rule for the window and door positions. In the figure 9, the room usually has window and door on the three sides facing to west (to kitchen), south (to floor), and north, since east side has heating system under the room's floor. The heating system is called "on-dol" in Korean, red square marked in the figure, burning wood blocks to heat air and ventilating hot air under space of the room.

The last selection is about furniture and props which were typically set in a room. Furniture was made of wood with metal decoration. Wardrobe and desk were most popular furniture in the period. Seating cushioned mat and rug was in a room for convenience. The people in Chosun sat on the floor then it was hard to find chairs.

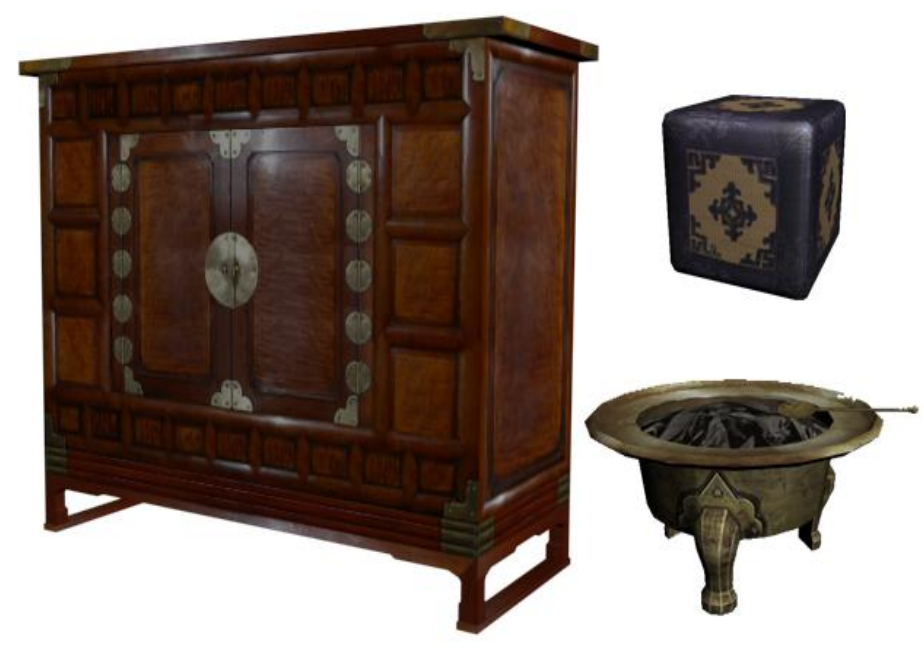

Fig. 10. Furniture and props

\subsection{Usage}

The application, Han Space Creator, is for the producers, who make film and media, and creators, who make background images for animation and games. When a film director plans to shot a historical drama, he first builds a set of the period. If he makes a film or drama which has the historical background of Chosun period, this is the right application to simulate the virtual set and camera walking.

The stage or set designer selects a town, which is on a flat field or on a mountainous area. By the Chinese geomantic principles, the most towns in Chosun were formed the place where mountain was in the backside and stream or river was in the front of the town. According to the residents' favor, many houses had the main gate toward to south or east to have more sunlight.

After setting town geographical features of the town, the designer may choose houses and place them in the town observing the Chinese geomantic principles. In the specific house, he may set windows, doors, furniture, props, and size of room. Depending on the room, it has props and furniture for men or women.

The director and designer finally navigate the virtual town by walk or fly. They can change the camera lens then view has variable depth of field and field of view angle. According to the lenses, focal lengths are different and scenic views vary.

Before building real sets, it is important to plan the construction schedule. This application saves money and time. Moreover Han Space Creator provides scholastically proven data for the set designers.

The animation directors and game developers may use Han Space Creator for making historical background by a few mouse clicks. Since Korean historical drams have been popular, the several game companies plan to release games of Chosun warriors.

Another use is for online personal blogs. The one of the biggest personal blog website is Cyworld ${ }^{\circledR}$ in Korea. Cyworld ${ }^{\circledR}$ offers free personal blog pages and sells some decoration items by theme or individually. However, it doesn't have Korean theme especially Chosun or other historical era. It stocks several traditional Korean items, but they are close to the Japanese style rather than Chosun. The problem is that the blog designers don't have enough knowledge of Chosun. The application can help him to create new Chosun theme package.

For education, it will be used as virtual museum or textbook of Korean history. The younger generation of Korea tends not to have any interest in the Korean history. As the internet is widespread, the younger people like to follow the foreign culture. As the application let them design a Chosun town for their blogs, they learned more about Chosun period.

\section{CONCLUSION}

The application is for who produces film and media, builds game graphics, and create 3D digital animation. It may used for personal online blogs to decorate the blogs' background or space. In Korea, there's dominant personal blog website, Cyworld.com ${ }^{\circledR}$. The service provider offers personal blog as free of charge, but it sells many items to decorate the blogs, music, graphic images, and space theme is the one of the items on sale. Cyworld.com ${ }^{\circledR}$ plans to service in English for foreign users since it is getting popular worldwide.

The foreign people are interested in the look of the Chosun period rather than the present shape of Korea since Korea has unique cultural heritage compared with Chinese' and Japanese' as their have own originality. As Korean cultural contents have spread wider, it is the time to set right models of Chosun Dynasty towns for the contents producers and the younger generation. The application will be the beginning of which represents the digital cultural contents of Chosun Dynasty. 


\section{ACKNOWLEDGMENT}

This work was supported by CT(Culture Technology) Institute Project of Korea Culture \& Content Agency (KOCCA) in 2008 .

\section{REFERENCES}

[1] Wikipedia online, Korean wave, March 2, 2009.

[2] Editorials, "Hanok(Korean Traditional House)", Jootaekmoonhwasa, 2006.

[3] Doojin, Hwang, "Hanok(Korean Traditional House) is Back", Kong-gansa, 2006.

[4] Dongjin, Kang, "Research of Yang-dong Village in Kyoungjoo", Korean Study Information Co., 2006.

[5] Dokyung, Kim, "Building Traditional Korean House", Hyunamsa, 2004.

[6] Namcheol, Joo, "Korean Doors and Windows", Daewon Press, 2001.

[7] Kihyun, Moon, "Daemok(Master Carpenter)", Korea Cultural Heritage Foundation, 2004

[8] Sanwoo, Seo, "Hanok(Korean Traditional House)", Sal-lim, 2005.

[9] Armstrong, Richard B., "Encyclopedia of Film Themes, Settings, and Series", McFarland \& Co., 2000.

[10] Ki-in, Jang, "Window and Door", Bosungkak, 1993.

[11] The Research Group of Korean House, "Korean House (Han-ok) and Space Culture", Gyomoonsa, 2005.

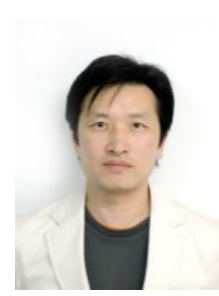

Seungmook Kang received B.S. degree from Western University, USA, in 1992 majored Mathematics and BFA degree of Art \& Tech in 1997 at The School of the Art Institute of Chicago, USA. In 2005, he received MFA degree in Electronic Visualization at University of Illinois at Chicago, USA. He is currently teaching 3D computer graphics at Jeonju University, Korea. His research interests include virtual reality applications in education and training system, haptic device, 3-D graphic visualization, stereoscopic, and interactive graphics and animation.

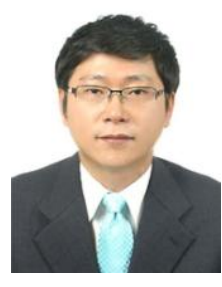

Hadong Kim is a 1989 management graduate of Chosun University, Korea. He completed New York University Stern MBA program and received MS degree in Computer Science Chonbuk University, Korea, in 2009. He now manages CGWave Inc., Korea, as a CEO. He accomplished many projects regarding culture content funded by Korea government. CGWave has created 3D games for disabled people and also developed real-time rendering software. 